\title{
Anti-cancer effect of betulin and its derivatives, with particular emphasis on the treatment of melanoma
}

\author{
Justyna Cabaj ${ }^{1, A-B, D \oplus}$, Weronika Bąk ${ }^{1, A-B, D \oplus}{ }^{\circ}$, Paula Wróblewska-Łuczka ${ }^{1, A, E-F \oplus ~}$ \\ ${ }^{1}$ Medical University, Lublin, Poland \\ A - Research concept and design, B - Collection and/or assembly of data, C - Data analysis and interpretation, \\ $D$ - Writing the article, E-Critical revision of the article, F- Final approval of article
}

Cabaj J, Bąk W, Wróblewska-Łuczka P. Anticancer effect of betulin and its derivatives, with particular emphasis on the treatment of melanoma. J Pre-Clin Clin Res. doi: 10.26444/jpccr/135691

\begin{abstract}
Introduction. Neoplastic diseases are a common cause of death, especially in developed countries. Various methods are used in cancer therapy including natural substances. Terpenes and terpenoids play a special role, including betulin and betulinic acid with the pentacyclic structure of lupane. They have a wide range of pharmacological activity, among which anti-cancer activity attracts the greatest attention.

Abbreviated description of the state of knowledge. The review discusses the pharmacological effects of betulin and its derivatives on tumours, and focuses on the potential of its application in the treatment of melanoma. The review study also presents future prospects for the use of this natural substance. Betulin and its derivatives have the ability to influence the processes of apoptosis, angiogenesis and autophagy. Additionally, they have the ability to sensitize, increasing the sensitivity to commonly used methods of cancer treatment. To-date, numerous studies have been carried out on the synthesis of betulinic acid derivatives, which would show greater polarity and activity compared to the starting compound. Due to their greater bioavailability, the modified compounds showed a stronger anti-tumour effect.

Conclusion. The results of the above-mentioned studies confirm the anti-cancer properties of betulin. Regarding melanoma, betulin shows significant therapeutic efficacy. This gives new perspectives for the treatment of the most dangerous skin cancer.
\end{abstract}

\section{Key words}

melanoma, triterpenes, betulin, betulinic acid

\section{INTRODUCTION}

Cancer is a group of diseases that are widespread and are the second biggest cause of death worldwide. In this inglorious ranking, only cardiovascular diseases are more deadly. In 2019, the estimated number of new tumor cases in the United States was approximately $1,762,450$, which means the staggering number of more than 4.800 new cases each day. Among them, 95,830 were skin melanoma. It has been estimated that 606,880 Americans will die from cancer in 2019 , equivalent to nearly 1,700 deaths a day $[1,2]$.

The incidence of melanoma, a malignant neoplasm originating from neuroectodermal melanocytic cells, has increased sharply in recent years, and is associated with increasing exposure to ultraviolet radiation and increased detection of this condition. Neoplastic changes appear more often on skin exposed to sunlight. There is a different frequency of occurrence depending on the geographic region, in which melanoma is relatively common among the inhabitants of Australia who have a fair complexion, and at the same time are exposed to large doses of sunlight. Intermittent and intense exposure in the early years of life is especially harmful. Genetic predisposition also plays an important role in the pathogenesis of melanoma [3].

Address for correspondence: Paula Wróblewska-Łuczka, Medical University, Lublin, Poland

E-mail: paula.luczka@umlub.pl

Received: 05.03.2021; accepted: 10.04.2021; first published: 21.04.2021
As with other neoplasms, the malignant transformation of melanomas follows a sequential genetic model that results in constitutive activation of oncogenic signal transduction. The activating mutation BRAF v600 is common. Further progression requires further mutations in, for example, the telomerase reverse transcriptase (TERT) promoter. Changes in the genes that control the cell cycle CDKN2A (cyclindependent kinase inhibitor 2A) allow for invasiveness. Finally, metastatic melanoma progression is associated with mutations in PTEN (phosphatase and tensin homolog deleted on chromosome 10) or p53 (TP53) protein [4]. Although melanoma is commonly associated with a skin lesion, it can also affect the oral mucosa, the anus and genitals, the esophagus, as well as the meninges and the eyeball. The basic features of melanoma are defined as alphabet 'ABC' asymmetry, border, colour, diameter, evolution [3].

Melanoma is the most dangerous skin cancer observed in clinical practice. It is characterized by high mortality due to its high metastatic potential and resistance to chemotherapy and radiotherapy. The median survival time of patients with metastases is only 6-9 months, and the 5-year survival rate is less than $1-2 \%$. Current therapy is based on surgery, chemotherapy and immunotherapy. Unfortunately, these methods are not always fully effective [5]. New treatment methods are based on anti-PD1 (PD1 - programmed death receptor 1) antibody therapy (pembrolizumab, nivolumab) and anti-CTLA-4 (anti-cytotoxic T cell antigen 4) (ipilimumab). In 2020, the first triple therapy combining BRAF/ MEK targeted immunotherapy and anti-PD-1 
immunotherapy with atezolizumab, vemurafenib and cobimetinib was approved for the treatment of inoperable or metastatic melanoma with BRAF v600 mutation, which occurs in approximately $40 \%$ of patients [6].

Research is constantly being carried out to find new methods of cancer therapy. A big problem concerns the serious side-effects of the synthetic drugs used in conjunction with conventional radio- and chemo-therapy. Natural compounds, due to their minimal side-effects, seem to be a favourable direction in the search for substances with anti-cancer properties, [7], as many natural products induce apoptosis and reduce resistance to chemotherapy by causing endoplasmic reticulum (ER) stress [8].

A promising group of compounds with anti-cancer properties are terpenes, which are widely distributed in the plant kingdom. Triterpenes constitute a group of 30-carbon compounds, among which lupane derivatives deserve special attention. One of them is betulin, which, especially with its oxidation product, i.e. betulinic acid, is a point of interest for many researchers (Fig. 1). Numerous studies have proved that, in addition to their anti-cancer activity, these compounds also have anti-inflammatory, immunomodulatory or antiviral properties [9]. Triterpenoids from the genus Gynostemma are widely used in traditional medicine, mainly in the treatment of diabetes, hypertension and obesity. These compounds are considered to be potential epigenetic modulators in the prophylaxis of breast cancer, and promising compounds in the prevention of lung and prostate cancer $[10,11]$.

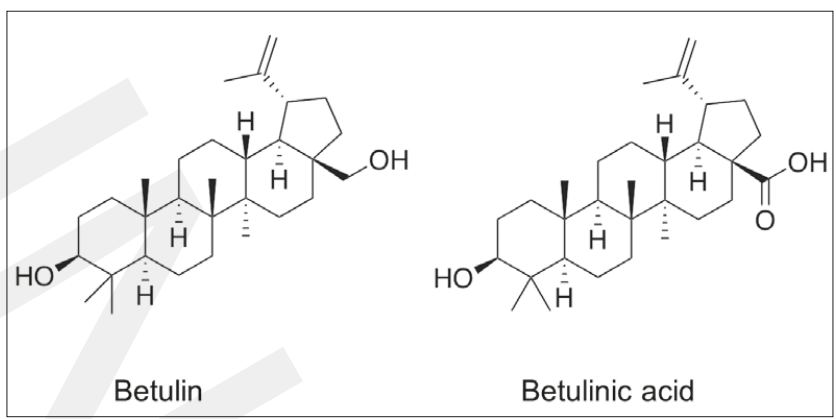

Figure 1. Structural formulas of betulin and betulinic acid

Betulin was first obtained in 1788 as a sublimation product from birch bark. It can also be isolated by extraction with organic solvents. Depending on the birch species, the betulin content in the obtained extracts ranges from $70-80 \%$. A certain limitation in the possibilities of its clinical application is its poor solubility in water $[9,12]$, although betulin is well soluble in pyridine or dimethyl sulfoxide [13]. The overall absorption rate of betulin is not sufficiently satisfactory, but its molecular structure makes it an excellent candidate for modification during chemical synthesis. Interestingly, betulin carbon atoms C-3 and C-28 have been shown to have $\mathrm{OH}$ groups, and their position, mutual distance and orientation in relation to the ring part of the betulin molecule are responsible for binding to active sites on the cell surface, thus for the biological activity betulin [14]. Betulin has the ability to easily derivatize with greater solubility. Betulinic acid, which seems to be the most important, was found for the first time in the extract of Gratiola officinalis [9, 12]. Soon afterwards, the first activity of betulinic acid as an antitumour compound against P388 cells of lymphocytic leukemia was described [15]. The $\log \mathrm{P}$ (partition coefficient), $\log \mathrm{D}$ (distribution coefficient) and $\log S$ (aqueous solubility) values suggest that betulinic acid is nonpolar and hydrophobic. These properties enable the penetration of betulinic acid through the bilayer lipid membrane of cells [16]. Nowadays, interest in this substance remains high, and research into new possibilities of its use is ongoing.

This review presents the mechanism of the anti-tumour activity of betulin and its derivatives, and focuses on its therapeutic efficacy in melanoma in order to gain an overview of the current status and future perspectives of treatment strategies for this cancer.

\section{CURRENT STATE OF KNOWLEDGE}

Effect on apoptosis. Apoptosis is called programmed, physiological cell death. It is a process necessary for the proper functioning of the body as it removes unnecessary, damaged and mutated cells. Both reducing and increasing the frequency of this phenomenon lead to serious consequences [17]. The most serious consequence of the deregulation of this process is the uncontrolled proliferation of cells associated with the development and progression of cancer and its resistance to pharmacotherapy [18]. During apoptosis, cells are fragmented and then removed from the tissues by phagocytosis. During programmed death, proteolytic enzymes are not released, so there is no inflammatory reaction, and the death of individual cells does not cause tissue destruction. The mechanism of apoptosis is complex, consisting of two routes. The first, known as external or receptor, is triggered by the Fas receptor, known as the death receptor. Upon binding to a ligand, the receptor interacts with the adapter protein through the death domains. The adapter molecule binds to inactive caspase 8 or 10 to form the DISC complex (death-inducing signaling complex), which in turn activates the effector caspase 3. A second pathway, called internal or mitochondrial, in response to stimulation causes cytochrome $c$ release from the mitochondria and activation of the death signal. Activation of this pathway is caused by cellular stress, i.e. DNA damage or changes in intracellular calcium concentration. Released cytochrome c forms a complex with the cytoplasmic protein Apaf1, which in turn activates caspase 9 , which activates caspase 3 , which has executive functions. Regulation of the apoptotic process is as complex as the process itself. It depends on many genes, among which p53 plays a special role which, together with its dependent protein, activates apoptosis. On the other extreme, there is the Bcl-2 protein which, in turn, inhibits this process $[17,19]$. Classically, p53 plays a role as guardian of the genome to limit the cell propagation. P53 induces cell cycle arrest, senescence, DNA repair, and apoptosis with corrupted genomes [20]. In most tumours, p53 is mutated. In melanoma, Wild-type (WT) p53 is found inactivated in some way in approximately $90 \%$ of cases with approximately 10\%-19\% carrying disabling point mutations. Melanocytes and melanoma cells are relatively resistant to the proapoptotic effects of $\mathrm{p} 53$ once it is activated. Moreover, UV induces p53 expression in melanocytes much less efficiently than in adjacent keratinocytes in the basal layer. Previously, resistance to $\mathrm{p} 53$ activation was considered to be an inherent property of melanocytes as they are programed to survive for the entire life of the organism, even with p53 induction by highly mutagenic UV light, and by the oxidative stress 
of melanin production. Despite this built-in resistance of melanocytes to $\mathrm{p} 53$ activation, virtually all melanomas likely require further silencing of $\mathrm{p} 53$ activity to achieve full growth and invasive potential. Currently, the main hypothesis explaining the low p53 mutation frequency in melanoma is that inactivation of the CDKN2A locus, which encodes the p16INK4A and p14ARF dual tumour suppressors, makes the p53 mutation unnecessary. Discovering the mechanisms that determine the low p53 mutation rate in melanoma and the way p53 WT is functionally inactivated, could lead to new approaches to $\mathrm{p} 53$ reactivation in melanoma treatment [21].

In cancer cells, apoptosis is often inhibited. A cell that does not undergo programmatical death divides despite its defects and passes them on to daughter cells [22]. Therefore, restoring cancer cells to apoptotic capacity is a potential target for anti-cancer drugs. The anti-carcinogenic effect of betulinic acid is manifested, inter alia, in the induction of apoptosis. This substance acts on the internal pathway, causing a loss of the mitochondrial membrane potential, resulting in the release of cytochrome $\mathrm{c}$ and the apoptotic induction factor, and ultimately cell death. It is also suggested that betulinic acid has the ability to modulate the activity of proteins from the Bcl-2 family, among which there are both pro-and antiapoptotic factors, and their balance determines cell survival. Betulinic acid, leading to an increase in the amount of proapoptotic protein Bax, leads to apoptosis $[23,24]$. The effect on the activity of the nuclear transcription factor NF- $\kappa$ B is another mechanism by which betulinic acid participates in the regulation of programmed death. Studies have shown that the induction of apoptosis can occur through both activation and inhibition of NF- $\kappa$ B. The action of betulinic acid on PC-3 prostate cancer cells resulted in a decrease in the expression of NF- $\kappa \mathrm{B}$. This produced a change in the $\mathrm{Bcl}-2$ / Bax protein ratio and the degradation of the nuclear repair enzyme (poly-ADP-ribose polymerase). These changes induced apoptosis [25]. In other studies, it was noted that after the use of betulinic acid, NF- $\kappa \mathrm{B}$, in turn, is activated in various tumour cell lines (including SH-EP neuroblastoma) and exerts pro-apoptotic activity depending on the type of cell [26]. Additionally, it was observed that under the influence of betulinic acid in neoplastic cells there was an increase in the level of reactive oxygen species, which activates cytosolic caspases and, consequently, apoptosis [27].

Effect on angiogenesis. Angiogenesis is essential for tumour growth. The formation of blood vessels enables the tumour cells to be supplied with oxygen and nutrients, and ensures the removal of metabolic products. Compared to normal blood vessels, tumour vascularization shows atypical morphological features. The tumour vascular network is characterized by dilated, tortuous and disorganized blood vessels. The angiogenesis process is strictly regulated. The most important stimulating factor is vascular endothelial growth factor (VEGF), produced under the influence of HIFla (hypoxiainducible factor 1a) under hypoxic conditions. Apart from VEGF, this process is stimulated by: fibroblast growth factor (FGF), angiopoietins (Ang1 and Ang2), platelet-derived growth factor (PDGF) and transforming growth factor $\beta$ (TGF $\beta$ ). Extracellular matrix metalloproteinases (MMPs) are essential for angiogenesis. Integrins also play an important role, mediating the process of adherence to endothelial cells, maintaining them in the right position and directed migration. Thrombospondin 1 (TSP1), next to anniostatin, enostatin or troponin, inhibits the process of vessel formation. Inhibitors of proangiogenic factors also show an inhibitory effect, among which metalloproteinase inhibitors (TIMP-1, TIMP-2, TIMP-3) are particularly important $[28,29]$.

Since the formation of new vessels growing into a neoplastic tumour is essential for disease progression and promotes metastasis, compounds that reduce the activity of angiogenesis-inducing factors are another therapeutic option in cancer control strategy. Research has shown that betulinic acid is able to inhibit tumour growth at the stage of angiogenesis. In a study using an endometrial adenocarcinoma cell culture (Ishikawa cell line) it was found that the anti-angiogenic potential of betulinic acid is associated with blocking the expression of prolidase, HIF-1 $\alpha$ and VEGF, and inhibiting collagen biosynthesis [30]. Another study showed that white birch bark triterpene inhibits angiogenesis by binding HIF-1 $\alpha$ and STAT3 (signal transducer and activator of transcription 3) to the VEGF promoter in PC-3 human prostate cancer cells [31]. On the other hand, the application of betulinic acid to acute myeloid leukemia (AML) cells increased activation of the aryl hydrocarbon receptor (AHR) with subsequent HIF-1a suppression [32]. Another study, this time in kidney cancer cell line (786-O and ACHN cells), betulinic acid was shown to down-regulate metalloproteinases MMP-2 and MMP-9 and vimentin, and up-regulate TIMP-2 and e-cadherin inhibiing the migration and invasion of neoplastic cells, which are key stages in the formation of metastasis [33].

Sensitization. The insensivity of neoplastic cells to therapeutic intervention is considered to be the main cause of therapeutic failure and mortality among cancer patients [34]. It is suggested that betulinic acid is a promising drug for increasing the radiosensitivity of oral squamous cell carcinoma. The CAL27 and Tca-83's lines were used in the research. Treatment with betulinic acid via Sp1 (specificity protein 1) sumoylation resulted in upregulation of PTEN protein expression. Sp1 is involved in cell growth, differentiation and apoptosis, and its over-expression in various types of cancer is associated with a worse prognosis. Spl's transcriptional activity is modulated by post-translational modifications, including sumoylation the attachment of the SUMO protein. By binding to a specific site on the PTEN promoter, SP1 increased its expression. PTEN, in turn, is an important tumour suppressor gene [35].

A large proportion of chemotherapy drugs works by inducing apoptosis. The ability of cancer cells to avoid this process determines the drug resistance. Research with the paclitaxel-resistant lung cancer cell line (H460) indicated that betulinic acid facilitates the process of programmed death. Summarizing the results obtained, it can be concluded that betulinic acid may be a useful drug in the treatment of drug-resistant lung cancer [36]. By interacting with GRP78 (the $78 \mathrm{kDa}$ glucose-regulated protein) and PERK (PKR-like endoplasmic reticulum kinase), betulinic acid inducses endoplasmic reticulum stress and apoptosis in taxolresistant breast cancer cell lines (MCF-7 and MDA-MB-231) [37]. Subsequent reports indicate that the combination of betulinic acid and 5-fluorouracil (5-FU) stops hedgehog signaling, which looms large in chemoresistance. Moreover, the combination of these two substances increased the chemosensitivity by inhibiting the GLI1, GLI2 (GLI family zinc finger proteins) and PTCH1 (protein patched homolog 1) genes in ovarian cancer cells (RMS-13) [38]. 
Impact on autophagy. Autophagy is a crucial process for the proper functioning of the body. It consists in 'eating' unnecessary or damaged fragments by the cell to obtain energy and rebuild the necessary molecules. The process of cellular component degradation takes place with the participation of lysosomes [17]. In cancer, autophagy can be both positive and negative. A beneficial phenomenon from the patient's point of view is the reduction in size of neoplastic cells, and the elimination of mutated parts that could enhance the mutagenesis process. On the other hand, this process allows these cells to survive under conditions of hunger and stress $[17,39,40]$.

A study published in 2019 found that betulinic acid induces apoptosis and autophagy, and was confirmed for the first time that the promotion of autophagy at an early stage can increase apoptosis. Additionally, it was found that betulinic acid does not exert a cytotoxic effect on normal liver cells [41].

Several molecules are involved in regulating autophagy, and the expression of the LC3-II, p62 and beclin-1 proteins plays an important role. The presented results show that the use of betulinic acid induced autophagy in HCC (hepatocellular carcinoma), as evidenced by LC3 (microtubule-associated protein 1A/1B-light chain 3) conversion, baclin-1 accumulation and downregulation of p62/SQSTM1 (ubiquitin-binding protein p62/sequestosome-1). These findings revealed that betulinic acid treatment promoted the death of hepatocellular carcinoma cells, not only by apoptosis, but also by autophagy [41, 42].

Anti-cancer effect of betulin and its derivatives on melanoma cells. Many studies have been carried out using betulin, betulinic acid and derivatives on melanoma cell lines (Tab. 1). To a large extent, their results have proved to be promising and have shown the therapeutic efficacy of this substance [43-55].

In 1995, a breakthrough study appeared in which betulinic acid was identified as a cytotoxic factor specific for melanoma. In studies in mice carrying human melanomas, tumour growth was completely inhibited without toxicity. As assessed, the anti-tumour effect was mediated by the induction of apoptosis. The obtained results initiated a wave of interest in this substance and resulted in numerous subsequent studies. The observation that betulinic acid is a highly selective substance active against human melanoma cells [43] led researchers to evaluate the effect of betulinic acid alone and in combination with radiotherapy on human melanoma. The results proved that Betulinic acid inhibited the growth of all tested melanoma cell lines. In addition, the effect of betulinic acid on melanoma cell lines was stronger than on primary melanocytes (Neo-II-tr and NeoIV-tr cell lines). Moreover, the effect of betulinic acid in combination with irradiation on cell survival proved to be clearly additive [44].

Initially, betulinic acid was thought to be selective for melanoma cells; however, researchers have shown that it induces apoptosis in both normal and cancerous melanocytes and affects keratinocytes. Apart from its cytotoxic activity in cellular systems, betulinic acid is capable of inducing the differentiation of normal human keratinocytes into corneocytes without immediately inducing apoptotic cell death [45]. Other studies have demonstrated the role of MAPK proteins (mitogen-activated protein kinase) in signalling programmed cell death induced by betulinic acid. It appears that the MAPK pathway is activated in response to the production of reactive oxygen species ROS. In addition to mediating these responses, betulinic acid treatment resulted in a gradual depolarization of the mitochondrial membrane potential, which contributed to the induction of programmed cell death [46].

The ability to form secondary tumours in places distant from the primary tumour is associated with the epithelialmesenchymal transition - EMT (epithelial-mesenchymal transition), in which immobile epithelial cells are able to change into invasive mesenchymal cells capable of movement. One study found that betulinic acid inhibited EMT in melanoma [47].

Polish scientists conducted experiments aimed at assessing the effect of betulin and its acetylene derivative - 28-O-propylylbetulin, on proliferation and apoptosis in the human melanoma cell line. Betulin and 28-O-propinoylbetulin inhibited cell proliferation with a concentration dependent degree. Cell cycle analysis showed

Table 1. List of melanoma cell lines and compounds tested on them - betulin, betulinic acid and derivatives

\begin{tabular}{|c|c|c|c|}
\hline Name of compound or derivative tested & $\begin{array}{l}\text { Melanoma cell line on which } \\
\text { the compound was tested }\end{array}$ & Tested concentration of betulin, betulinic acid and derivatives on the cell line & References \\
\hline Betulinic acid & A $375,518 A 2$, MES20, MES21 & $1-10 \mu \mathrm{g} / \mathrm{ml}$ & [44] \\
\hline Betulinic acid & UISO-Mel-1 & 4 and $8 \mu \mathrm{g} / \mathrm{ml}$ & {$[46]$} \\
\hline Betulinic acid & A375 & $2.5-50 \mu \mathrm{M}$ & [47] \\
\hline Betulin and 28-O-propynoylbetulin & G-361 & $0.1-10 \mu \mathrm{g} / \mathrm{ml}$ & [48] \\
\hline Betulin and amino acid esters of betulin & $\mathrm{Me}-45$ & $\begin{array}{l}0.75-100 \mu \mathrm{M} \text { (betulin: } \mathrm{IC} \mathrm{C}_{50}=30.5 \mu \mathrm{M} \text {; betulinic acid: } \mathrm{IC} \mathrm{C}_{50}=15.3 \mu \mathrm{M} \text {; betulin } \\
\text { derivatives containing lysine } \mathrm{IC}_{50}=2.456 \mu \mathrm{M} \text { and ornithine } \mathrm{IC}_{50}=2.465 \mu \mathrm{M} \text { ) }\end{array}$ & [49] \\
\hline Betulin & B164A5, B16F10 & $1-150 \mu \mathrm{M}$ (for B164A5: IC $C_{50}=1.9 \mu \mathrm{M}$; for B16F10: IC $50=2.5 \mu \mathrm{M}$ & {$[50]$} \\
\hline $\begin{array}{l}\text { Modified betulin-conjugated gold } \\
\text { nanoparticles }\end{array}$ & A375, B164A5 & 10 and $50 \mu \mathrm{M}$ betulin and equivalent of betulin & {$[51]$} \\
\hline Modified betulin silver nanoparticles & B164A5 and B16Ova & $\begin{array}{l}0.5-100 \mu \mathrm{M} \text { (betulin: for B164A5 IC }{ }_{50}=4.269 \mu \mathrm{M} ; \text { for B16Ova IC } C_{50}=3.89 \mu \mathrm{M} ; \\
\text { betulin silver nanoparticles: for B164A5 IC }=0.9301 \mu \mathrm{M} ; \\
\left.\text { for B16Ova IC } C_{50}=20.26 \mu \mathrm{M}\right)\end{array}$ & {$[52]$} \\
\hline $\begin{array}{l}\text { Betulin, 3-phosphate derivatives of } \\
\text { betulin }\end{array}$ & Hs 294T & Betulin $\mathrm{IC}_{50}=44.04 \mu \mathrm{M}$; phosphate derivatives of betulin $\mathrm{IC}_{50}=3.01-69.15 \mu \mathrm{M}$ & {$[54]$} \\
\hline Betulinic acid derived amides & A375 & Betulinic acid IC $\mathrm{C}_{50}>30 \mu \mathrm{M}$; betulinic acid derived compounds $\mathrm{IC}_{50}=1.48-3.14 \mu \mathrm{M}$ & [55] \\
\hline
\end{tabular}


an increase in the fraction of dead cells after incubating the cells with betulin and 28-O-propinoylbetulin. The cytotoxic effect was more pronounced with 28-O-propyloylbetulin. Caspase-3 activity in 28-O-propynylbetulin-treated cells was almost 2-fold higher compared to cells incubated with betulin. The observed results confirmed that the obtained derivative is a stronger anti-cancer agent [48]. In other experiments, betulin esters were shown to have greater antitumour activity compared to the unmodified precursor.

The properties of betulin are limited due to its poor solubility in water; therefore, in the conducted study (current study?), betulin was modified with selected natural amino acids. Modified compounds due to greater bioavailability and better concentration in human metastatic melanoma cells showed a stronger cytotoxic and pro-apoptotic effect [49]. Research is constantly being undertaken to create ever-newer betulin derivatives in order to improve its anticancer effectiveness. Polish researchers have synthesized a series of 3-phosphate derivatives. Their in vitro antiproliferative activity was then assessed against five human cell lines, including melanoma (Hs 294T). Two of the compounds obtained, namely 3-diethoxyphosphoryl-28propyloylbetulin and 3-diethoxyphosphorylbetulinic acid, showed higher activity against the melanoma cell line compared to betulin. Additionally, 3-diethoxyphosphoryl28-propyloylbetulin turned out to be more effective than cisplatin used as the reference compound [54]. Another study showed the effectiveness of amides derived from betulinic acid and platonic acid. All obtained compounds proved to be cytotoxic to various human tumour cell lines. Particularly high cytotoxicity were distinguished by benzyl $2 \beta$, 33-diacetyloxy-lup-20 (29) -en-28-amide, quinolin-5-yl $2 \beta, 3 \beta$-diacetyloxy-lup-20 (29) -en-28-amide and isoquinolin4 -yl $3 \beta$-acetyloxy-lup-20 (29) -en-28-amide, acting mainly by inducing apoptosis. The isoquinolin-4-yl $3 \beta$-acetyloxy-lup-20 (29) -en-28-amide compound turned out to be the most cytotoxic to melanoma cells, and simultaneously much less cytotoxic to fibroblasts [55]. The results of the cited studies show that simple changes in the structure of betulin can provide new compounds with enhanced anti-cancer activity.

The wide application of metallic nanoparticles in biomedical fields has revealed new possibilities of functionalisation of anti-cancer agents in order to obtain better therapeutic properties and reduce their toxicity [56]. In recent years, metallic nanoparticles have been studied for their use in anti-cancer therapy as drug delivery systems. Gold nanoparticles are one example which have unique properties that allow them to be widely used in biomedicine. They are neutral, stable, highly dispersed, have no cytotoxic activity, and are biocompatible. In a 2018 study, betulinloaded gold nanoparticles were synthesized. It has been hypothesized that the conjugation with gold will improve the bioavailability of the drug, and thus its anti-cancer properties, because, as already mentioned several times, betulin's main disadvantage is its poor solubility in water, which reduces its bioavailability. The results showed that betulin-coated gold nanoparticles showed a dose-dependent cytotoxic effect, and induced apoptosis of neoplastic cells in human melanoma cell lines - A375 and murine melanoma - B164A5. Therefore, they can be considered a new therapeutic strategy for patients with melanoma [51]. Promising results were also obtained in a study in which betulin was coupled with silver nanoparticles, demonstrating the anti-tumour efficacy of the obtained combination [52]. Like gold nanoparticles, silver nanoparticles are also widely used in biomedical fields for their therapeutic properties. They exhibit cytotoxic activity by increasing the levels of reactive oxygen species and increasing lipid peroxidation. Additionally, they cause chromosomal aberrations and DNA damage, thus generating the phenomenon of genotoxicity [53].

Antigens neoplastic are capable of eliciting an antineoplastic response from the host's immune system. A number of studies indicate the importance of dendritic cells in this process. They participate in the induction of an immune response from $\mathrm{T}$ lymphocytes, presenting tumour antigens [57]. They are also responsible for the production of IL-12 (interleukin-12), which has an anti-tumour effect by inhibiting angiogenesis and stimulating the cytotoxicity of T lymphocytes and NK (natural killer) cells, as well as the activation of macrophages and other food cells [58].

New directions of cancer treatment focus on the search for compounds that combine cytotoxicity against cancer cells with the ability to modulate the immune response. Researchers showed that betulin, in addition to its proapoptotic and antiproliferative activity in various melanoma cell lines, also has highly specific immunostimulatory activity regarding the activity of dendritic cells. A measure of this activity was the release of the cytokine IL-12p70. Additionally, it turned out that betulin strongly increased the production of IFN $\gamma$ (interferon $\gamma$ ) and IL-2, which is a sign of increased activity of CD8 + T cells. The obtained results suggest that the increased activity of dendritic cells caused by the action of betulin resulted in an increase in the activity of T lymphocytes [50].

In vivo animal studies have confirmed the anti-tumour activity of betulin and its derivatives. Histopathological analysis of the changes showed that PEGylated betulin derivative with silver nanoparticles reduced the tumour volume and inhibited the development of secondary neoplasms [52]. The anti-tumour activity of betulin in a complex with a cyclodextrin derivative was tested on C57BL/ $6 \mathrm{~J}$ mice. This complex significantly reduced tumour volume and diameter after 14 days of treatment [59].

Melanoma is a significant problem, not only for humans, but also for animals. Dermatological disorders are common in horses and skin cancers account for approximately 50\% of all equine cancers. Malignant melanoma occurs mainly in gray horses. There are currently no local treatment options [60], although triterpenoids may be promising substances for topical treatment. Naturally occurring betulinic acid and the synthetically modified derivative of NVX-207 (3-acetyl-betulinic acid -2-amino-3-hydroxy-2 hydroxymethylpropanoate) have been shown to exert antiproliferative and cytotoxic effects in in vitro equine melanoma cells [61-63]. Both substances have the ability to induce apoptosis in equine melanoma cells by inducing initiating caspases (caspases -8 and -9) and, consequently, activating the effector caspase -3 [63]. Moreover, sufficient penetration and permeation of both compounds in the isolated skin of equines was noted [62]. In an in vivo study in the skin of horses, good systemic tolerance and only mild local sideeffects were observed [60].

An important barrier preventing the active use of triterpenes as anti-cancer agents is their poor solubility in water, which means that they cannot achieve their goals in vivo, and to achieve the desired therapeutic effect it 
is necessary to use them in high doses which, in turn, is burdened with numerous side-effects. A possible solution to this problem is the use of hybrid structures based on triterpenoids and penetrating cations. Recently, conjugates of betulinic acid and lipophilic cation F16 (E-4-(1H-indol-3ylvinyl)-N-methylpyridinium iodide) have been synthesized, which already at sub-micromolar concentrations showed a significantly enhanced effect compared to the parent betulinic acid [64]. Mitochondrial dysfunction underlies the cytotoxic activity of these compounds based on lipophilic cation F16 [65].

\section{CONCLUSION}

The role of triterpenes of natural origin as potential drugs is indisputable, although their content in plant material is generally low. Betulin, however, is one of the exceptions, accounting for up to $25 \%$ of the outer bark layer of various birch species. It is used to synthesize anti-inflammatory, anti-viral, anti-malarial and anti-cancer drugs. Interest in betulin has been constant since the last century, with newer and newer reports on the results of research on its molecular interactions. Research is continually underway on its structural modifications that will allow for better therapeutic effects.

The results of the research quoted in the study confirm the anti-cancer effect of betulin. It can be used together with commonly used chemotherapeutic drugs, a combination that may prove helpful in eliminating drug-resistant cells. Attempts to use betulin as a precursor in the synthesis of new derivatives have resulted in the obtaining of compounds with improved anti-cancer and pharmacokinetic properties. Betulin compounds and its derivatives are also effective in the anti-cancer therapy of melanoma.

\section{REFERENCES}

1. Roser M, Ritchie H. Cancer. https://ourworldindata.org/cancer, access: 2021.01.24

2. Siegel RL, Miller KD, Jemal A. Cancer statistics. CA A Cancer J Clin 2019; 69: 7-34. https://doi.org/10.3322/caac.21551

3. Kumar V, Abbas AK, Aster JC, red. wyd. pol. Olszewski WT. Robbins Patologia. Edra Urban \& Partner. 2019.

4. Schadendorf D, van Akkooi ACJ, Berking C, et al. Melanoma. Lancet. 2018; 392(10151): 971-984. doi: 10.1016/S0140-6736(18)31559-9

5. Bębenek E, Chodurek E, Orchel A, et al. Antiproliterative activty of novel acetylenic derivatives of betulin against G-361 human melanoma cells. Acta Pol Pharm. 2015; 72(4): 699-703.

6. Moreira A, Heinzerling L, Bhardwaj N, et al. Current Melanoma Treatments: Where Do We Stand? Cancers. 2021; 13: 221. https://doi org/10.3390/cancers13020221

7.Król SK, Kiełbus M, Rivero-Müller A, et al. Comprehensive review on betulin as a potent anticancer agent. Biomed Res Int. 2015; 2015: 584189. doi: $10.1155 / 2015 / 584189$

8. Kim C, Kim B. Anti-Cancer Natural Products and Their Bioactive Compounds Inducing ER Stress-Mediated Apoptosis: A Review. Nutrients. 2018; 10(8): 1021. https://doi.org/10.3390/nu10081021

9. Hordyjewska A, Ostapiuk A, Horecka A, et al. Betulin and betulinic acid: triterpenoids derivatives with a powerful biological potential Phytochem Rev. 2019; 18: 929-951. https://doi.org/10.1007/s11101-01909623-1

10. Li S, Kuo HD, Yin R, et al. Epigenetics/epigenomics of triterpenoids in cancer prevention and in health. Biochem Pharmacol. 2020; 175: 113890. https://doi.org/10.1016/j.bcp.2020.113890

11. Nguyen NH, Ha TKQ, Yang JL, et al. Triterpenoids from the genus Gynostemma: Chemistry and pharmacological activities.
J Ethnopharmacol. 2021; 268: 113574. https://doi.org/10.1016/j jep. 2020.113574

12. Amiri S, Dastghaib S, Ahmadi M, et al. Betulin and its derivatives as novel compounds with different pharmacological effects. Biotechnol Adv. 2020; 38: 107409. https://doi.org/10.1016/j. biotechadv.2019.06.008

13. Kuznetsova SA, Skvortsova GP, Maliar IN, et al. Extraction of betulin from birch bark and study of its physico-chemical and pharmacological properties. Russ J Bioorg Chem. 2014; 40: 742-747. https://doi. org/10.1134/S1068162014070073

14. Pospíšil M, Kovář P, Vácha R, et al. Study of the betulin molecule in a water environment; ab initio and molecular simulation calculations. J Mol Model. 2012; 18: 367-376. https://doi.org/10.1007/s00894-0111055-y

15. Trumbull ER, Bianchi E, Eckert DJ, et al. Tumour Inhibitory Agents from Vauquelinia corymbosa (Rosaceae), J Pharm Sci. 1976; 65(9) 1407-1408. doi: 10.1002/jps.2600650938

16. Khan MF, Nahar N, Rashid RB, et al. Computational investigations of physicochemical, pharmacokinetic, toxicological properties and molecular docking of betulinic acid, a constituent of Corypha taliera (Roxb.) with Phospholipase A2 (PLA2). BMC Complement Altern Med. 2018; 18(1): 48. https://doi.org/10.1186/s12906-018-2116-x

17. D'Arcy MS. Cell death: a review of the major forms of apoptosis, necrosis and autophagy. Cell Biol Int. 2019; 43: 582-592. https://doi.org/10.1002/ cbin.11137

18. Pistritto G, Trisciuoglio D, Ceci C, et al. Apoptosis as anticancer mechanism: function and dysfunction of its modulators and targeted therapeutic strategies. Aging (Albany NY). 2016; 8(4): 603-619. https:// doi.org/10.18632/aging.100934

19. Singh R, Letai A, Sarosiek K. Regulation of apoptosis in health and disease: the balancing act of BCL-2 family proteins. Nat Rev Mol Cell Biol. 2019; 20: 175-193. https://doi.org/10.1038/s41580-018-0089-8

20. Hsieh CC, Shen CH, The Potential of Targeting P53 and HSP90 Overcoming Acquired MAPKi-Resistant Melanoma. Curr. Treat. Options in Oncol. 2019; 20: 22 https://doi.org/10.1007/s11864-019 $0622-9$

21. Box NF, Vukmer TO, Terzian T. Targeting p53 in melanoma. Pigment Cell Melanoma Res. 2014; https://doi.org/10.1111/pcmr.12180

22. Pfeffer CM, Singh A. Apoptosis: A Target for Anticancer Therapy. Int J Mol Sci. 2018; 19(2): 448. https://doi.org/10.3390/ijms19020448

23. Fulda S, Scaffidi C, Suzin S, et al. Activation of mitochondria and release of mitochondrial apoptogenic factors by betulinic acid. J Biol Chem. 1998; 273(15): 33942-8. doi: 10.1074/jbc.273.51.33942

24. Kumar P, Bhadauria AS, Singh AK, Saha S. Betulinic acid as apoptosis activator: Molecular mechanisms, mathematical modeling and chemical modifications. Life Sci. 2018; 209: 24-33. https://doi.org/10.1016/j. lfs.2018.07.056

25. Rabi T, Shukla S, Gupta S. Betulinic acid suppresses constitutive and TNF-alpha-induced NF-kappaB activation and induces apoptosis in human prostate carcinoma PC-3 cells. Mol Carcinog. 2008; 47: 964-973. doi: $10.1002 / \mathrm{mc} .20447$

26. Kasperczyk H, La Ferla-Bruhl K, Westhoff M, et al. Betulinic acid as new activator of NF-kappaB: molecular mechanisms and implications for cancer therapy. Oncogene. 2005; 24(46): 6945-6956. doi: 10.1038/ sj.onc. 1208842

27. Wick W, Grimmel C, Wagenknecht B, et al. Betulinic acid-induced apoptosis in glioma cells: A sequential requirement for new protein synthesis, formation of reactive oxygen species, and caspase processing. J Pharmacol Exp Therapeut. 1999; 289: 1306-1312.

28. Rajabi M, Mousa SA. The Role of Angiogenesis in Cancer Treatment. Biomedicines. 2017; 5(2): 34. https://doi.org/10.3390/ biomedicines5020034

29. Viallard C, Larrivée B. Tumour angiogenesis and vascular normalization: alternative therapeutic targets. Angiogenesis. 2017; 20(4): 409-426. https://doi.org/10.1007/s10456-017-9562-9

30. Karna E, Szoka Ł, Pałka J. Betulinic acid inhibits the expression of hypoxia-inducible factor 1 alpha and vascular endothelial growth factor in human endometrial adenocarcinoma cells. Mol Cell Biochem. 2010; 340(1-2): 15-20. doi: 10.1007/s11010-010-0395-8

31. Shin J, Lee HJ, Jung DB, et al. Suppression of STAT3 and HIF-1 alpha mediates anti-angiogenic activity of betulinic acid in hypoxic PC-3 prostate cancer cells. PLoS One. 2011; 6(6): e21492. doi: 10.1371/journal. pone.0021492

32.Zhang H, Li L, Huang X, et al. Combination of betulinic acid and chidamide inhibits acute myeloid leukemia by suppression of the HIF1a pathway and generation of reactive oxygen species. Oncotarget. 2017; 8(55): 94743-94758. doi: 10.18632/oncotarget.21889 
33. Yang C, Li Y, Fu L, et al. Betulinic acid induces apoptosis and inhibits metastasis of human renal carcinoma cells in vitro and in vivo. J Cell Biochem. 2018; 119: 8611-8622. https://doi.org/10.1002/jcb.27116

34. Lenart K, Szyda A, Kiełbasiński M, Duś D, et al. Kliniczne skutki oporności wielolekowej w nowotworach; Onkologia w praktyce klinicznej 2005, tom 1, nr 1 .

35. Yuan DY, Meng Z, Xu K, et al. Betulinic acid increases radiosensitization of oral squamous cell carcinoma through inducing Spl sumoylation and PTEN expression. Oncol Rep. 2017; 38(4): 2360-2368. doi: 10.3892/ or. 2017.5872

36. Zhan XK, Li JL, Zhang S, et al. Betulinic acid exerts potent antitumour effects on paclitaxel-resistant human lung carcinoma cells (H460) via $\mathrm{G} 2 / \mathrm{M}$ phase cell cycle arrest and induction of mitochondrial apoptosis. Oncol Lett. 2018; 16(3): 3628-3634. doi: 10.3892/ol.2018.9097

37. Cai Y, Zheng Y, Gu J, et al. Betulinic acid chemosensitizes breast cancer by triggering ER stress-mediated apoptosis by directly targeting GRP78. Cell Death Dis. 2018; 9(6): 636. https://doi.org/10.1038/s41419-0180669-8

38. Wang YJ, Liu JB, Dou YC. Sequential treatment with betulinic acid followed by 5 -fluorouracil shows synergistic cytotoxic activity in ovarian cancer cells. Int J Clin Exp Pathol. 2015; 8(1): 252-259.

39. Yun CW, Lee SH. The Roles of Autophagy in Cancer. Int J Mol Sci. 2018; 19(11): 3466. https://doi.org/10.3390/ijms19113466

40. Li YJ, Lei YH, Yao N, et al. Autophagy and multidrug resistance in cancer. Chin J Cancer. 2017; 36(1): 52. https://doi.org/10.1186/s40880017-0219-2

41. Liu W, Li S, Qu Z, et al. Betulinic acid induces autophagy-mediated apoptosis through suppression of the PI3K/AKT/mTOR signaling pathway and inhibits hepatocellular carcinoma. Am J Transl Res. 2019; 11(11): 6952-6964.

42. Kma DL, Baruah DTJ. The interplay of ROS and the PI3K/Akt pathway in autophagy regulation. Biotechnol Appl Biochem. 2021. https://doi. org/10.1002/bab.2104

43. Pisha E, Chai H, Lee IS, et al. Discovery of betulinic acid as a selective inhibitor of human melanoma that functions by induction of apoptosis. Nat Med. 1995; 1(10): 1046-1051. doi: 10.1038/nm1095-1046

44. Selzer E, Pimentel E, Wacheck V, et al. Effects of Betulinic Acid Alone and in Combination with Irradiation in Human Melanoma Cells. J Invest Dermatol. 2000; 114(5): 935-940. doi: 10.1046/j.1523-1747.2000.00972.x

45. Galgon T, Wohlrab W, Dräger, B. Betulinic acid induces apoptosis in skin cancer cells and differentiation in normal human keratinocytes. Exp Dermatol. 2005; 14(10): 736-743. https://doi.org/10.1111/j.16000625.2005.00352.x

46. Tan Y, Yu R, Pezzuto JM. Betulinic acid-induced programmed cell death in human melanoma cells involves mitogen-activated protein kinase activation. Clin Cancer Res. 2003; 9(7): 2866-2875.

47. Gheorgheosu D, Jung M, Ören B, et al. Betulinic acid suppresses NGALinduced epithelial-to-mesenchymal transition in melanoma, Biol Chem. 2013; 394(6): 773-781. https://doi.org/10.1515/hsz-2013-0106

48. Orchel A, Kulczycka A, Chodurek E, et al. Influence of betulin and 28-O-propynoylbetulin on proliferation and apoptosis of human melanoma cells (G-361). Postepy Hig Med Dosw. 2014; 68: 191-177. doi: $10.5604 / 17322693.1088757$

49. Drąg-Zalesińska M, Drąg M, Poręba M, et al. Anticancer properties of ester derivatives of betulin in human metastatic melanoma cells (Me-45). Cancer Cell Int. 2017; 17: 4. https://doi.org/10.1186/s12935016-0369-3
50. Pfarr K, Danciu C, Arlt O, et al. Simultaneous and dose dependent melanoma cytotoxic and immune stimulatory activity of betulin. PLoS One. 2015; 10(3): e0118802. https://doi.org/10.1371/journal. pone. 0118802

51. Mioc M, Zinuca PI, Ghiulai R, et al. The Cytotoxic Effects of BetulinConjugated Gold Nanoparticles as Stable Formulations in Normal and Melanoma Cells. Front Pharmacol. 2018; 9: 429. doi: 10.3389/ fphar.2018.00429

52. Danciu C, Pinzaru I, Coricovac D, et al. Betulin silver nanoparticles qualify as efficient antimelanoma agents in in vitro and in vivo studies. Eur J Pharm Biopharm. 2019; 134: 1-19. https://doi.org/10.1016/j. ejpb.2018.11.006

53. Wei L, Lu J, Xu H, et al. Silver nanoparticles: synthesis, properties, and therapeutic applications. Drug Discov Today. 2015; 20(5): 595-601. https://doi.org/10.1016/j.drudis.2014.11.014

54. Chrobak E, Kadela-Tomanek M, Bębenek E, et al. New phosphate derivatives of betulin as anticancer agents: Synthesis, crystal structure, and molecular docking study. Bioorg Chem. 2019; 87: 613-628. doi: 10.1016/j.bioorg.2019.03.060

55. Hoenke S, Heise NV, Kahnt M, et al. Betulinic acid derived amides are highly cytotoxic, apoptotic and selective. Eur J Med Chem. 2020; 207 112815. https://doi.org/10.1016/j.ejmech.2020.112815

56. Sharma H, Mishra PK, Talegaonkar S, et al. Metal nanoparticles: a theranostic nanotool against cancer, Drug Discov Today. 2015; 20(9): 1143-1151. https://doi.org/10.1016/j.drudis.2015.05.009

57. Roliński J. The role of dendritic cells in haematologic neoplasms immunotherapy. Post Nauk Med. 2000; 4: 47-50.

58. Gołąb J, Jakóbisiak M, Lasek W, et al. Immunologia. Warszawa: Wydawnictwo Naukowe PWN; 2017.

59. Soica C, Dehelean C, Danciu C, et al. Betulin complex in $\gamma$-cyclodextrin derivatives: properties and antineoplasic activities in in vitro and in vivo tumour models. Int J Mol Sci. 2012; 13(11): 14992-15011. doi: 10.3390/ijms131114992

60. Weber LA, Puff C, Kalbitz J, et al. Concentration profiles and safety of topically applied betulinic acid and NVX-207 in eight healthy horses-A randomized, blinded, placebo-controlled, crossover pilot study. J Vet Pharmacol Ther. 2021; 44(1): 47-57. https://doi.org/10.1111/jvp.12903

61. Liebscher G, Vanchangiri K, Mueller T, et al. In vitro anticancer activity of Betulinic acid and derivatives thereof on equine melanoma cell lines from grey horses and invivo safety assessment of the compound NVX207 in two horses. Chemico-Biological Interactions. 2016; 246: 20 - 29. https://doi.org/10.1016/j.cbi.2016.01.002

62. Weber LA, Meißner J, Delarocque J, et al. Betulinic acid shows anticancer activity against equine melanoma cells and permeates isolated equine skin in vitro. BMC Vet Res. 2020; 16(44): 1- 9. https://doi.org/10.1186/ s12917-020-2262-5

63. Weber LA, Funtan A, Paschke R, et al. In vitro assessment of triterpenoids NVX-207 and betulinyl-bis-sulfamate as a topical treatment for equine skin cancer. PLOS ONE. 2020; 15(11): e0241448. https://doi.org/10.1371/ journal.pone. 0241448

64. Spivak AY, Nedopekina DA, Gubaidullin RR, et al. Pentacyclic triterpene acid conjugated with mitochondria-targeting cation F16: Synthesis and evaluation of cytotoxic activities. Med Chem Res. 2021; 30: 940-951 https://doi.org/10.1007/s00044-021-02702-z

65. Dubinin MV, Semenova AA, Ilzorkina AI, et al. Mitochondria-targeted prooxidant effects of betulinic acid conjugated with delocalized lipophilic cation F16. Free Radic Biol Med. 2021; 31: S0891-5849(21)00196-9. https://doi.org/10.1016/j.freeradbiomed.2021.03.036 